\title{
ON TWO NEW SPECIES OF DORCOPSIS FROM THE SOUTH COAST OF NEW GUINEA.
}

\author{
By N. de Miklouho-Maclay.
}

\section{(Plate XX.)}

Further examination of the New Guinea Collection in the Macleay-Museum, resultedin finding twonew species of Dorcopsis, a short description of which is the subject of this paper.

Both skins had been purchased from Mr. Goldie, who obtained them in the vicinity of Hanuabada (1), (Village of Port Moresby), on the South Coast of New Guinea.

Though the skulls had suffered a great deal by the mode of preservation (in common salt), already mentioned in a former paper (2), a sufficient examination of the same was still possible, which enabled me to decide without doubt, that in the first place, the specimens belonged to the genus Dorcopsis; secondly, that they were distinct from each other ; and thirdly, that they were distinct also from the other species of the genus that are known.

I believe that the reasons why they should be included in the genus are--the breadth of the premolars, the existence of small canines in the upper jaw, the general shape of the skull, and the direction forward of the hair on the nape of the neck.

I shall describe the two new species as Dorcopsis Beccarii, and Dorcopsis Macleayi, in honour of two men of science, whose works have contributed materially to our present knowledge of the Natural History of New Guinea.

(1) During the last stay of Rev. W. G. Lawes in sydney, I had the opportunity of ascertaining the right pronunciation aud way of spelling of the name of the large village of Port Moresby. Although some natives call the place " Anuapada," others again "Anuabata," the greater number however, pronounce this name in such a way that the Missionaries of the London Mission Society, have agreed to spell it as " Hanuabada." In the dialect of the Motu tribe, "Hanua" means " big" or "large," "Bada" " inhabited land " or "village."

(2) Proceed. of the Linn. Soc of N.S.W., Vol. IX. Part 4, p. 892. 


\section{Dorcopsis BeccariI. N. sp. (Figs. 1-4.)}

Adult $q$ from the hills in the vicinity of Hanuabada, on the South Coast of New Guinea. (Skin at the Macleay Museum.)

Some measurements taken on the skin :-

$\begin{array}{llllll}\text { From tip of nose to end of tail... } & \ldots & \ldots & \ldots & 1,000 \mathrm{~mm} . & 39,7 \mathrm{in} .\end{array}$

$\begin{array}{lllllllll}\text { Length of tail } & \ldots & \ldots & \ldots & \ldots & \ldots & \ldots & & \ldots \\ \end{array}$

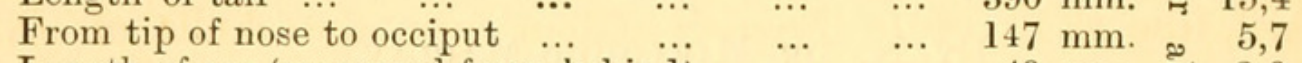

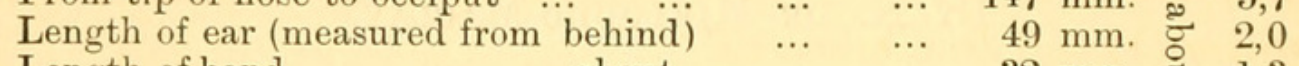

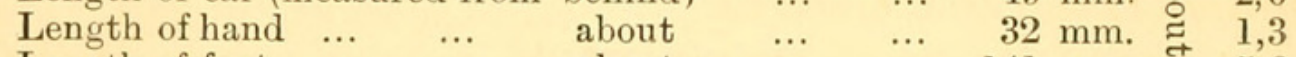

$\begin{array}{llllllll}\text { Length of foot } & \ldots & \ldots & \ldots & \text { about } & \ldots & \ldots & 141 \mathrm{~mm} .\end{array}$

4 nipples in the pouch.

Colour of fur: Dark grey, with a brownish tinge. The back, hands and feet very little darker than the breast, and only near the arms and on the base of the tail the brownish grey fur appears slightly tinged with rufous.

Each hair (of the back) is dark grey on the base, and of a much lighter tint for nearly $\frac{2}{3}$ of the hairs length.

The muzzle with a deep median groove is bare and covered with a black scaly skin.

The large glandular hairfollicles on the laryngeal region are 3 in number, but not placed exactly in the median line (as is the case in Dorcopsis luctuosa and Dorcopsis Chalmersii.) Similar hairfollicles appear as well on the upper lip, over the inner canthus of the eye, and other's some distance behind and below theouter canthus.

Ears not large, with some light brown hair on the posterior margin near the meatus; the inside of the concha nearly bare, showing blackish skin.

The hair on the nape of the neck of Dorcopsis Beccarii is as in D. luctuosa and D. Chalmersii directed forward. The converging point between the shoulders is $195 \mathrm{~mm}$., (about 7,7in.) behind the behind the occiput.

The tip of the tailis white and bare, showing large elongated scales.

The skull of Dorcopsis Beccarii (Fig. 1) resembles that of Dorcopsis Brunii, of which very good representations are given on the plates appended to the work of Schlegel and Müller (1) ; it is

(1) H. Schiegel en S. Müller: Over drie Biudeldieren uit de familie der kengoeroes (published as a part of the Verhandelingen over de Natuurlijke Geschiedenis der Nederlandsche overezesche Bezittengen door de Leden der Naturkundige Commissie en andere Schrijvers, uitgegeven op last van den Koning door C. T. Temminck, 1839-1844. Plates XXXIII. and XXIV. 
very elongated and as in the skull of $D$. Brunii, the 2 marked ridges of the parietalia, running from the orbital margin of the frontal bone, join together in a median crest, which extends over the interparietal hone towards the superior anterior margin of the occipital bone. This median parieto-occipital crest is a point in which the skull of $D$. Beccarii differs from the skulls of $D$. luctuosa (1) and D. Chalmersii.

The apex of the angular process of the inferior margin of the zygoma corresponds with the anterior cusps of the 3rd molar. The nasal bones are in the middle, a little narrower than on both ends, which character has also been noticed in D. Brunii.

The Palate presents 8 well marked transverse folds without counting a few (6) smaller ones in the anterior corner of the palate, between the canines and the incisors. About the disposition of these folds I refer to fig. 2.

One large posterior Palatine foramen with several very much smaller behind on each side.

The median upper Incisors of $D$. Beccarii, present the character of the genus, being much larger than the lateral ones, which appears to be, in the specimen of the Macleay Museum, very much worn down and does not show any indication of cusps on their lower margin, as is the case in D. luctuosa and D. Chalmersii.

About the size (length) of the canines our specimen cannot be considered as a standard for the species (3). The distance from the canine to the premolar (measured on the base of the respective teeth) is $3 \frac{1}{2}$ times the distance between the canine and the 2 nd lateral incisor.

The breadth of the upper Premolars, from before backwards, is quite as great as of the two molars together with the anterior

(1) A. H. Garrod: On the kangaroo called Halmaturus luctuosens, \&c., \&c. Proceed. Zool. Soc., 1875. Plate VII.

(2) Schlegel en Müller: Loc. cit., p. 137.

(3) As already stated, the skulls of the specimens of the two species of Dorcopsis which description form the subject of this paper, had unfortunately suffered a great deal, by the mode of preservation, so that the minor details of the detition could therefore not be discerned, as for instance: I could not decide, if the lower margin of the lateral incisors is cuspidated or not, could not judge about the size and shape of the canines, etc., etc., in removing the crust of magnesia the enamel has been also very likely partly removed. 
cusps of the third (1). On the external surface of the tooth, from the cingulum several ridges with intervening depressions run at right angles to the cutting edge which in $D$. Beccarii is a little curved and not so distinctly cuspidated as in D. luctuosa. The anterior part of the tooth, examined from the external (labial) side is a trifle higher than the posterior. On the internal (lingual) side, the ridges and the depressions are less marked.

Examined from below (looking at the base of the skull) the external and internal outlines of the premolar, are not quite parallel, but there is an inflection noticeable on the internal outline which corresponds also with the narrowest transversal diameter of the tooth.

Out of the 4 molars, only the first is a little worn down as well as the cusps of the second. The fourth molar is the smallest and the posterior portion (cusp) of the same is smaller than the anterior, in which peculiarity the fourth molar differs from the other molars which have the two portions (cusps) nearly of the same size.

In $D$. Beccarii, the molars with the premolars form not two parallel straight, but two slightly curved lines converging more behind than in the front. [The distance between the two most prominent points of the internal side of the premolar being $18 \mathrm{~mm}$., and that between the corresponding joints of the molars $15 \mathrm{~mm} .(2)]$

In the lower jaw, the incisors are rather narrow and straight. The Premolars are scarcely less broad than in the upper jaw, and present the same proportion of breadth in relation to the first, second and third molar of the lower jaw as in the upper.

The slightly cuspidated cutting edge of the Premolar, examined from the side, is curved, the posterior end being the highest point of the same; viewed from above, the edge is also not straight, but convex outwards. Similar to the upper Premolar, the inuer

(1) The size of the premolars of D. luctuosa, in comparison with the size of the molars, present exactly the same proportion (Vide Garrod, On Halmaturus luctuosa, etc., etc. Loc. cit., p. 54.)

(2) This case proves that the arrangement of the teeth, premolars and molars, on both sides of the upper jaw, forming straight lines parallel one to the other, cannot, as Garrod supposed (loc. cit., p, 53), be regarded as a constant cranial character, which distinguishes Dorcopsis as a genus from Macropus. 
surface of the Mandibular premolar does not present any kind of tubercles (as is the case in D. luctuosa and D. Chalmersii.

Like in the upper jaw, the first mandibular mollar is the most worn down, as well as the cusps of the second.

\section{Dorcopsis Macleayi. N. sp.}

(Figs. 5-9.)

Habitat.-Wouth Coast of New Guinea, inland from Hanuabada. Stuffed specimen at the Macleay-Museum.

Some measurements taken on the skin before it was stuffed :From the tip of nose to the end of tail... $\quad \ldots \quad \ldots \quad 790 \mathrm{~mm} . \quad \circ 31,2 \mathrm{in}$. \begin{tabular}{lllllllll} 
Length of tail & $\ldots$ & $\ldots$ & $\ldots$ & $\ldots$ & $\ldots$ & $\ldots$ & $320 \mathrm{~mm}$ & \\
\hline & 13,8
\end{tabular} From occiput to the tip of nose... $\quad \ldots . \quad \ldots . \quad \ldots .112 \mathrm{~mm}$. $\begin{array}{lllllllll}\text { Length of the foot } & \ldots & \ldots & \ldots & \ldots & \ldots & 115 \mathrm{~mm} . & \cong & 4,5\end{array}$

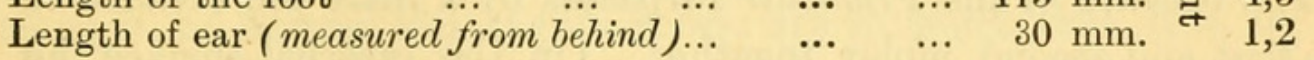

General Colour: Dark brownish grey, a little lighter on the ventral side.

Muzzle bare, black, slightly divided in the middle. The three conspicuous glandular hair follicles on the throat are not symmetrically disposed.

Ears very small.

The hair on the nape of the neck of $D$. Macleayi presents in its direction a very peculiar deviation from the usual direction of the hair of the neck of the other Dorcopside, presenting two centres of irradiation of the hair, one above the other (one near the ccciput, the other on the back between the shoulder, $140 \mathrm{~mm}$. behind the occiput) instead of one, as is the case in D. Mulleri, D. luctuosa D. Chalmersii, D. Beccarii. Fig. 9 is added to illustrate this peculiar direction of the hair of the neck, and will give, I hope, a better idea of it than a long description. The end of the tail is nearly bare, for about $100 \mathrm{~mm}$., (about 4 in.) white and scaly on the tip.

The skull of $D$. Macleayi presents many points of similarity with D. Beccari. A glance at plate XX. will easily prove this statement. The former is only in proportion to its breadth (from zygoma to zygoma) shorter than the latter. We find in skull of $D$. Macleayi the same median parieto-occipital crest, the same inflection on the external outline of the nasal bone as in D. Beccarii. 
Looking at the base of the skull of D. Macleayi, we see a similar disposition of the 8 palatine folds to that of D. Beccarii. The arrangement of the teeth of the upper jaw forms in the former, less curved lines than in the latter, only the two posterior (4th) molars standing a trifle nearer together than the two third molars of the same jaw.

The lateral incisors are here also in proportion much smaller than the median ones, the second lateral a little larger than the first.

The canines are of about the same size as the first lateral incisor, but longer and much more pointed. The distance from the canine to the premolar is 3 times the distance from the canine to the posterior incisor.

The breadth of the Premolar surpasses by a little the breadth of the first and second molar together. On the internal surface the posterior portion of the premolar presents a small roundish inflection of the size of a pins head.

In the lower jaw, the incisors are narrow. The premolar comparatively smaller than in the upper jaw, its breadth being equal to that of the first molar and a part of the second (corresponding to the anterior portion of the tooth to the ridge of the second, or posterior cusp). The posterior portion of the cutting edge is elevated, a triangular tubercle which gives the tooth a characteristical aspect, different from the lower premolars of other species of Dorcopsis.

\section{EXPLANATION OF PLATE. XX.}

Fig. 1.-Skull of Dorcopsis Beccarii Maclay, from above.

Fig. 2.-A part of the same skull to show the dentition and the palatine fold.

Fig. 3.-Under jaw of the same skull.

Fig. 4.-Sideview of both jaws of the same.

Fig. 5. - Skull of Dorcopsis Macleayi Maclay, from above.

Fig. 6. - Palatine fold and dentition of the upper jaw of the same skull.

Fig. 7.-Under jaw of the same.

Fig. 8. - Side view of both jaws of the same.

Fig. 9.-Diagram showing the direction of the hair on the neck of Dorcopsis Macleayi. Centre of irradiation.

(All the figures, with the exception of fig. 9, natural size. 


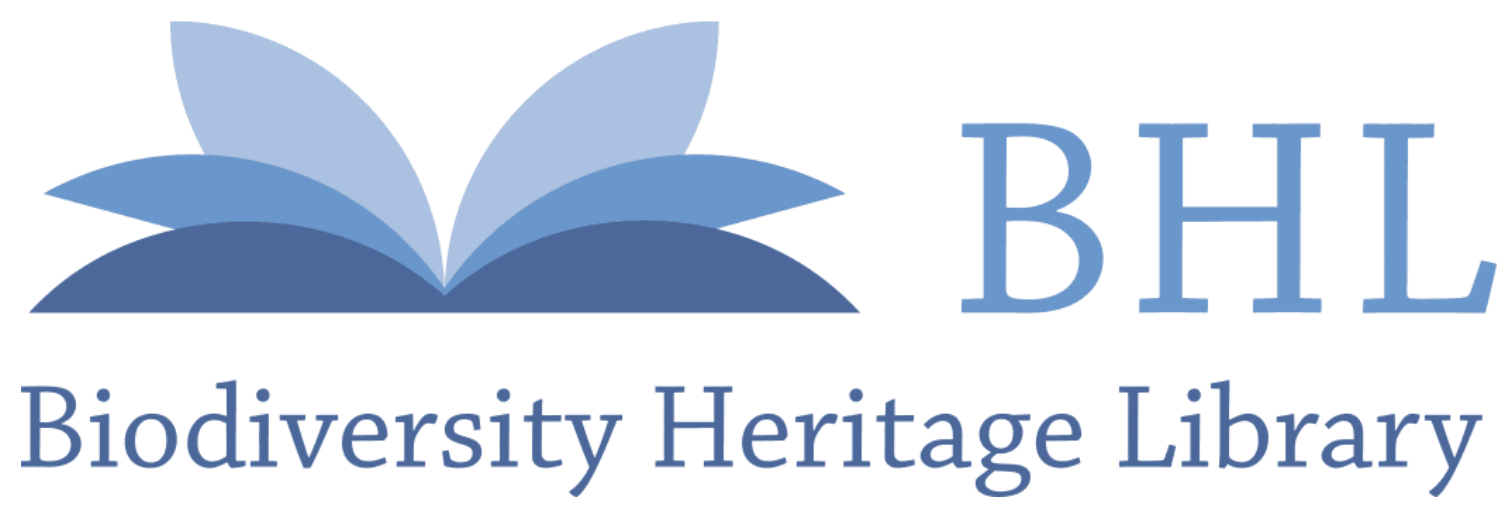

Miklouho-Maclay, N De. 1885. "On two new species of Dorcopsis from the south coast of New Guinea." Proceedings of the Linnean Society of New South Wales 10, 145-150. https://doi.org/10.5962/bhl.part.17908.

View This Item Online: https://www.biodiversitylibrary.org/item/30482

DOI: https://doi.org/10.5962/bhl.part.17908

Permalink: https://www.biodiversitylibrary.org/partpdf/17908

\section{Holding Institution}

MBLWHOI Library

\section{Sponsored by}

MBLWHOI Library

\section{Copyright \& Reuse}

Copyright Status: NOT_IN_COPYRIGHT

This document was created from content at the Biodiversity Heritage Library, the world's largest open access digital library for biodiversity literature and archives. Visit BHL at https://www.biodiversitylibrary.org. 